\title{
Social Network Based Learning Management System
}

\author{
Hassan Najam Ali ${ }^{1}$, Dr. Purnomo Budi Santoso, Msc., Ir. ${ }^{2}$, \\ Dr. Muhammad Aziz Muslim, ST, MT $^{3}$ \\ ${ }^{1}$ Magister of Information Technology and Communication, Brawijaya University, Indonesia) \\ ${ }^{2,3(I n f o r m a t i o n ~ T e c h n o l o g y ~ a n d ~ C o m m u n i c a t i o n ~ D e p a r t m e n t, ~ B r a w i j a y a ~ U n i v e r s i t y, ~ I n d o n e s i a) ~}$
}

\begin{abstract}
The fact that 77 percent of the world population are using mobile phones that can be used to access the internet. Furthermore, social network and e-learning can create a combination and rise in a beneficial means. The purpose is to enhance the benefit of social network as a media to enhance education. By making the e-learning as an embedded feature inside the social network, knowledge share and gathering among users and the source can be unlimited. The system is so called social network based learning management system. This system made the administrator as the owner of learning contents able to manage their knowledge shares and virtual courses. The test done by applying 74 test cases which cover all functions in social network based LMS, had resulted $100 \%$ functional. The positive means of the system is that activities in LMS are published over the Facebook members that jois the course, and key activities are published only to members' social friends. The architecture of social network in Facebook has made learning to have more social benefit. Additionally, there are inputs for the system to improve further: the need to perform online examination, more managed discussion, and video chat for real-time learning.
\end{abstract}

Keywords: social network lms, facebook lms, facebook social lms, facebook education, facebook learning

\section{Introduction}

Learning has taken into new era to ease learner to gain their knowledge through internet, everywhere, anywhere, and anytime. It can be done by accessing internet based learning media or e-learning. The fact that there are 5.3 billion mobile subscribers (that's 77 percent of the world population) means that they are using mobile phones that can be used to access the internet. Mobile growth is being driven by demand of developing world.

Years have been proved that Facebook being acknowledge by developers because of its platform, called the Facebook Platform. It only requires skill in Web programming language such as PHP or Java. Its popularity is rising throughout the years because of its structured environment and social network, but its Facebook Platform is proving to be a critical means to prevent Facebook to be the latest favourite. Because of third-party applications, Facebook has stimulated more and more users to participate in it.

Meanwhile in an article [9], e-learning can best be understood as any type of learning delivered electronically. Defined broadly, this can encompass learning products delivered by computer, intranet, internet, satellite, or other remote technologies. Brandon Hall, a noted e-learning researcher, defines e-learning as "instruction delivered electronically wholly by a web browser, through the Internet or an intranet, or through CD-ROM or DVD multimedia platforms." Increasingly, the common understanding of e-learning relates exclusively to web-based training -- or learning products delivered via a web browser over a network. Book in [11] says that investment analysis team deems e-learning as a technology that fully leverages the distributive power of the Internet and encourages investors to consider the "e" in e-learning to represent "effective".

With the powers both Facebook as social network and LMS as learning media, there is a good opportunity to integrate these application to create beneficial means of education within social network popularity.

\section{Facebook Application Model}

A good model of web application is shown in Fig. 1. This model illustrates the common architecture of web application, where application is located at a web server. In this model, users who wanted to access particular application have to go to specific URL. 


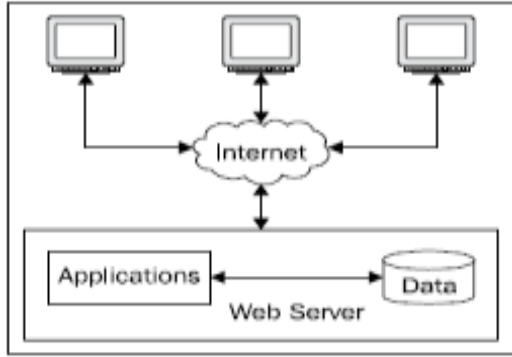

Fig. 1. Web application model

On the other hand, Facebook has its own web application model (Fig. 2.) that enables user to access any Facebook application without knowing the URL.

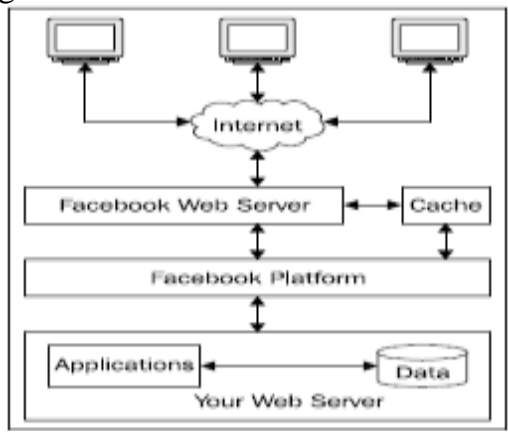

Fig. 2. The Facebook web application model

In Fig. 2. It is obvious that the purpose of that model is to provide an interface between the application and Facebook. Moreover, it also employs a cache to accommodate millions of hits in the application and to run normally the Facebook common features. Facebook Platform is the tools that accommodate those functionalities. This platform contains three elements Facebook API, FBML, FBJavascript and FQL. Detail of each elements can be found in Facebook's Developers page, as briefly explained below.

\subsection{Facebook API}

API stands for Application Programming Interface, as defined in book [7] API is a set of software libraries that enables developers to work with an application without knowing anything about its internal workings. So, by using Facebook API, anyone can develop any Facebook applications easily and unlimitedly with only required skills in web programming.

\subsection{FBML}

FBML is Facebook Markup Language. It has the same structure as common HTML, only additional tags related to Facebook features.

\subsection{FQL}

Information that is stored in Facebook are actually securely saved in Facebook's database. To be able to reach the database, the only way is to use FQL (Facebook Query Language). It is similar to previously known SQL (Structured Query Language).

\subsection{FB Javascript}

FBML does not support the use of standard JavaScript using the script element. However, Facebook JavaScript (or FBJS, for short) allows for limited scripting functionality inside a Facebook application.

\section{Learning Management System}

A learning management system (commonly abbreviated as LMS) is a software application for the administration, documentation, tracking, and reporting of training programs, course room and online events, elearning programs, and training content. As described in [4], a robust LMS should be able to do the following:

- centralize and automate administration

- use self-service and self-guided services

- assemble and deliver learning content rapidly

- consolidate training initiatives on a scalable web-based platform

- $\quad$ support portability and standards 
- $\quad$ Personalise contents and enable knowledge reuse.

More described at [4], LMSs range from systems for managing training and educational records, to software for distributing courses over the Internet with features for online collaboration. Corporate training uses LMSs to automate record-keeping and employee registration. Student self-service (e.g., self-registration on instructor-led training), training workflow (e.g., user notification, manager approval, wait-list management), the provision of on-line learning (e.g., Computer-Based Training, read \& understand), on-line assessment, management of continuous professional education (CPE), collaborative learning (e.g., application sharing, discussion threads), and training resource management (e.g., instructors, facilities, equipment), are dimensions to Learning Management Systems.

\section{System Framework}

From the point of view of Facebook and Learning Management System, there are differences but there are also facts that enhancing each other. From the transparency and share-ability of Facebook and the unlimited distance and highly interactive learning of LMS, the integration of an LMS to Facebook will enhance each purpose. Facebook will no longer entertainment, fun, mostly wasting time for young people, it will be educational and LMS will be as acceptible as it built inside Facebook.

Entering a virtual course is as easy as logging in Facebook, students activities is more transparent since every activity in virtual course is shared as their status, new learning material is as easy as tag-share feature in Facebook, and more other features.

As seen for the most Facebook user from ages range from 18 to 25 year old. The LMS that will be developed is for college students, because of the independency of subjects found in college.

\subsection{System Design}

Because the system is basically a website-based application, it has sitemap that will help users to navigate in the application. The LMS itself is built in a separate web server (www.hassanhoma.com). And the integration is done by creating an application in Facebook by visiting https://developers.facebook.com. In the site, there are complete guides to create a new Facebook application.

The sitemap for the system is adapting from recommended design in article [6]. It will display all necessary features as seen below.

- Facebook Login

- Facebook Frontpage

- Notifications

> Friend Requests

) Messages

> Network Notifications

- Home

- Profile

- Account

$>$ Logout

- Facebook Apps

> LMS Course page (student)

- Basic Info

Notification of any announcement, displaying and accessing current course(s)-chapters-resourcesassessment, request to join course. All these feature are developed as host features, the LMS.

- Collaborative/Interactive Learning

Document shares, creative commons, and discussions. This part of LMS is developed using Facebook Social Plugin - Comments and Live Stream, which enables user activities as mentioned.

- Administratif Information

Display Lecturer information, schedules, displaying attendance list, displaying progress, displaying grade. All these features are developed as host features, which is the LMS.

$>\quad$ LMS Course page (lecturer)

- Home

List of student's requests, approval, and deny student request to join a course. All features are developed as host features.

- New Courses

Create, edit, delete course. Give detail information about course. This feature enables lecturer defines course detail which provided by forms.

- Courses

Edit and delete detailed course (including related resource and assessment), as host feature. 
- Discussion

Lecturer can manage any posted discussion. This feature is implementing Facebook Social Plugin Comments and Live Stream.

- Reports

Manage student grade and progress in host feature.

$>$ Department Head page

- Approving lecturers and choosing their course and denying lecturers request.

- Approving and denying students request.

- Checking lecturers or Students

\subsection{Data Flow Diagram}

In Fig. 3., a Data Flow Diagram for the system illustrates the work of the LMS with specific user data and functions.

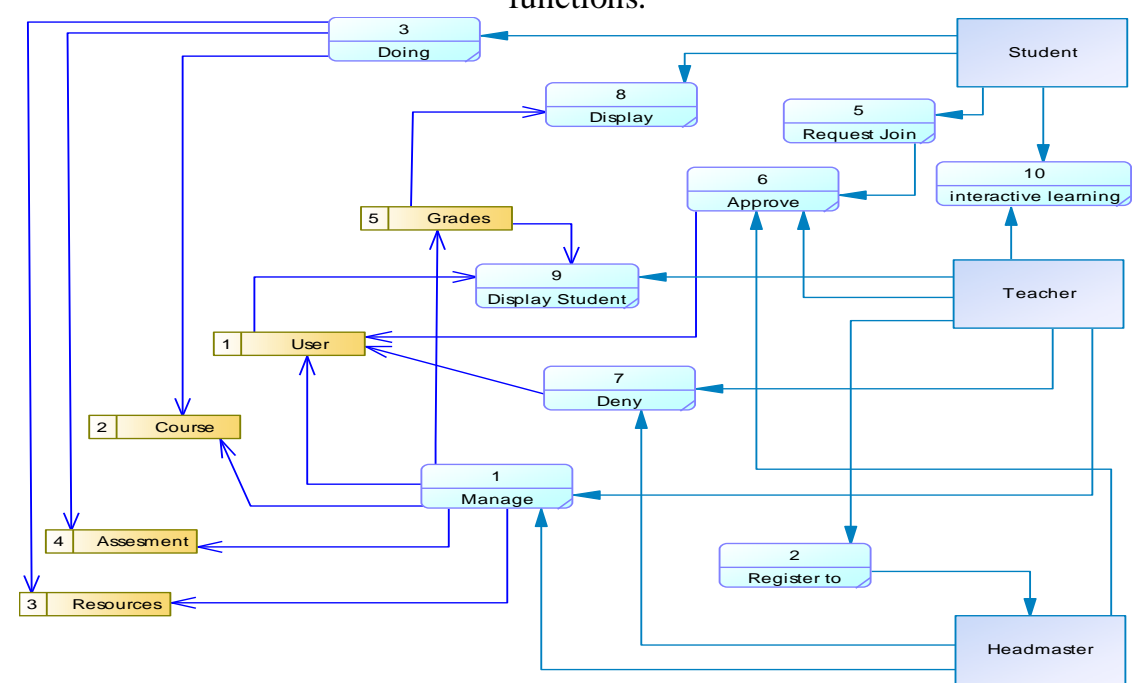

Fig. 3. LMS Data Flow Diagram

\subsection{Database}

According to the DFD, database is shown in Fig. 4., here, all user's data will be stored and managed by each of functionality. The database is implemented in a web server where LMS resides.

\subsection{System Requirements}

Social Network based LMS can be built if all requirements are met, here are the requirements for the system to work:

\subsubsection{Host Server}

Host server is the location where web-based LMS will be built. This web server must have unique name like http://www.hassanhoma.com or other available name.

\subsubsection{Facebook application Development}

Facebook application development is located in developers.facebook.com, developer must own a Facebook account, and logged in before creating new application (social_lms). And the important part for the integration is Facebook code, including App ID and App Secret. The address of the application is https://apps.facebook.com/social_lms/.

If configuration and information of new application is saved and no error, Facebook will create new unique Application ID (App ID) and Application secret code (App Secret). An example of successful Facebook application is seen below. 


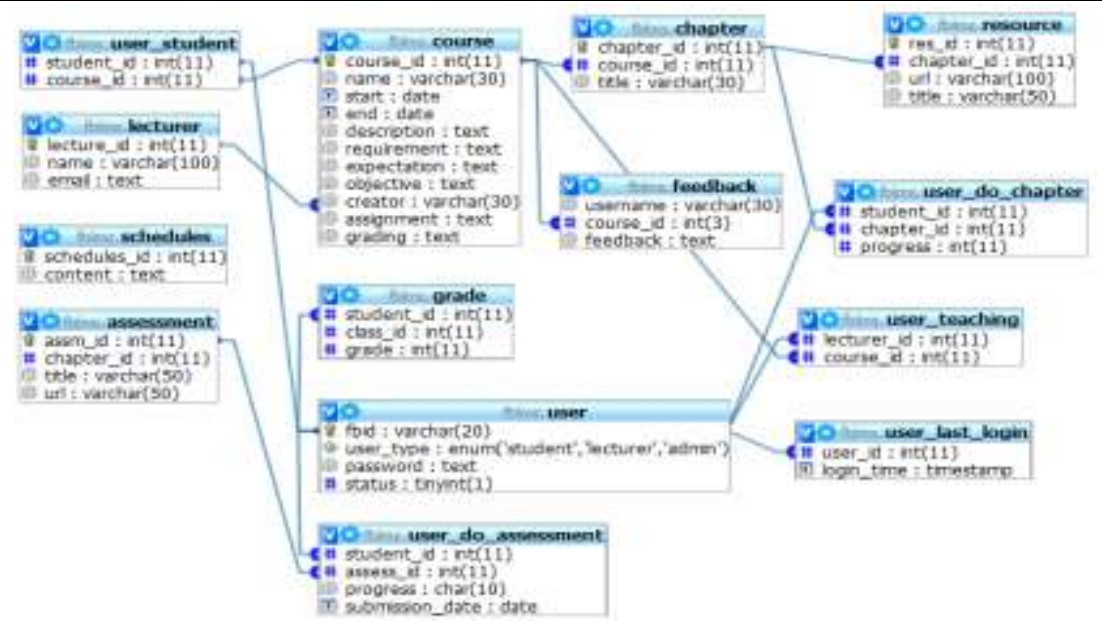

Fig. 4. Database implementation

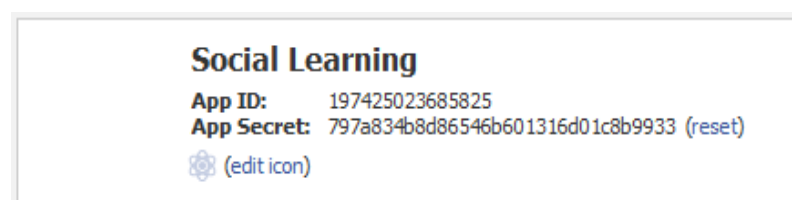

Fig. 5. Generated code of new FB Application

\subsubsection{Social Network features for LMS}

Social network features that can be inserted into the application are using Social Plugins. Social Plugins enable you to provide engaging social experiences to your users with just a line of HTML. Because the plugins are served by Facebook, the content is personalized to the viewer whether or not they have signed into your site.

Comments: Comments Box is a social plug-in that enables user commenting on Discussion topic. Features include moderation tools and distribution.

Social Relevance: Comments Box uses social signals to surface the highest quality comments for each user. Comments are ordered to show users the most relevant comments from friends, friends of friends, and the most liked or active discussion threads, while comments marked as spam are hidden from view.

Distribution: Comments are easily shared with friends or with people who like LMS application on Facebook. If a user leaves the "Post to Facebook" box checked when posts a comment, a story appears on his/her friends' News Feed indicating that he/she's made a comment on LMS, which will also link back to host site.

Friends and people who like the Page can then respond to the discussion by liking or replying to the comment directly in the News Feed on Facebook or in the Comments Box on your site. Threads stay synced across Facebook and on the Comments Box on your site regardless of where the comment was made. As seen in Fig. 6.

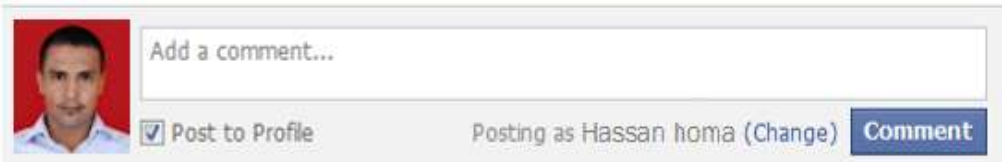

Fig. 6. Facebook Comment

Live Stream: The Live Stream plugin lets users visiting LMS and share activity and comments in real time. Live Stream works best when students or lecturer doing activities inside LMS, for instance, discussion on a particular subject.
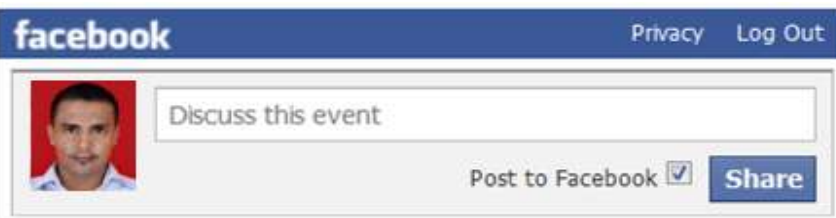

Fig. 7. Facebook Live Stream 


\section{System Testing}

Software testing is a critical element of software quality assurance and represents the ultimate review of specification, design, and code generation. For this application the test will be using black box testing that will be divided into two tests procedures which are LMS host test and Facebook integration and features tests.

LMS host test will test all features that are built as proprietary features, to make sure all features works as designed. Test case is taken from LMS site map and contents, divided onto three kinds of users (Department Head, Lecturer and student). Facebook integration tests the integration of LMS site into Facebook and each feature that uses Facebook Social Plugin. The test was not covering for usability and visual appearance.

The tests for the users are 74 cases, of which results is $100 \%$ functional in the user perspective. Additionally, there limitations that in the future can be added into the application to enrich the features, which listed below:

1. Unable to perform examination or assessment online, all done by opening the examination or assessment task and send the result to email address stated in the task.

2. Discussion is unlimited for all students and lecturers, which it should be restricted to certain user for example: course member only.

3. Video chat for live stream learning is not available in the application, video chat can be held separately using another application.

\section{Conclusions}

The test done by applying 74 test cases which cover all functions in social network based LMS, resulted $100 \%$ performance, in which the functions are working as it supposed to be. The positive means of the system is that activities in LMS is published over the Facebook members that joins the course, and key activities are published only to members' social friends, of which help socialize LMS widely. The architecture of social network in Facebook has ease learning to have social benefit.

Additionally, there are limitation of the system that needs to be improved further: the need to perform online examination, more managed discussion, and video chat for real time learning. Consequently, at which Facebook continuously developing their system, there are good opportunity to enhance the LMS to have more features that related to social network powers.

\section{Acknowledgements}

The author would like to acknowledge thesis supervisors, Dr. Purnomo Budi Santoso.Msc.Ir and Dr. Muhammad Aziz Muslim, ST, MT , for the advices and the team that have been working so hard to build the system and friends, that had voluntarily helps the tests.

[1] Myers, G., The Art of Software Testing, Wiley, 1979.

[2] ADLNET. (2001). Guidelines for Design and Evaluation of Web-Based ADL Applications. [On-Line]. Available: http://www.adlnet.org.

[3] Economy. [On-Line]. Available: http://www.learnativity.com/marketreports.html

[4] Ellis, Ryann K, Field Guide to Learning Management System. 2009.

[5] Hall, B, Web-Based Training Cookbook: everything you need to know about online training. 1997.

[6] Harris, Kerry-Lee and Jones, Deborah, Creating Effective Websites for University Teaching - An educational framework. University of Melbourne : Melbourne. 2007.

[7] Hayder, Hasin and Dr Bain, Alexander Mark, Learning Facebook Application Development. Pack Publishing : Birmingham. 2008.

[8] John Wiley \& Sons, NY. Also see: www.brandon-hall.com.

[9] Kodone, Susan, PhD. An E-Learning Primer. Raytheon Interactivity : Florida. 2001.

[10] Merrill, D.M. Instructional strategies that teach. CBT Solutions. Nov-Dec. p. 1-11. 1997.

[11] Morgan Keegan. E-learning Investment Reports. E-Learning: The Engine of the Knowledge .2001.

[12] Royce, W. W. Managing the development of large software systems: concepts and techniques. Proc. IEEE WESTCON, Los Angeles CA: IEEE Computer Society Press. (Ch.4) . 1970.

[13] Sommerville, Ian. Software Engineering. Addison-Wesley. 2007.

[14] Wagner, Richard. Building Facebook Application for Dummies. Wiley Publishing: New Jersey. 2008. 